\title{
Study regarding the Determination of the Flammability Characteristics of the Residue Collected from Natural Gas Transport
}

\author{
Maria Prodan ${ }^{1, *}$, Emilian Ghicioi ${ }^{1}$, Irina Nalboc $^{1}$, Andrei Szollosi-Mota ${ }^{1}$, and Sonia Suvar ${ }^{1}$ \\ ${ }^{1}$ Safety Mineral Recources Departament, National Institute for Research and Development for Mine Safety and Protection to Explosion, \\ INSEMEX Petrosani, G-ral Vasile Milea, 32-34, Petrosani, Hunedoara, Romania
}

\begin{abstract}
In the natural gas pipelines, the so-called black powder is formed. It can take many forms, including wet tarred substance or fine dry powder. Black powder occurs in both newer and older natural gas pipelines. This can disrupt the distribution of natural gas either by interrupting distribution to the customer or by reducing the quality of products delivered to customers. This residue, black powder can damage operations that take place in the transport pipelines, such as reduced inspection accuracy, erosion of the control valve and reduced flow. In addition, this powder also presents a health hazard due to the fact that it may contain pyrophoric sulphides, which require specific handling and storage procedures. Black powder is a solid contaminant found in natural gas distribution systems around the world. Drilling mud, dust, construction dirt, sand, iron oxide, iron carbonate, iron sulfides, welding slag, salt crystals, valve grease, corrosion inhibitors, and other organic materials can contribute to the formation and the presence of this residue, also called black powder. In this paper were analyzed the flammability properties of black powder collected from natural gas transmission pipelines of an operator in Romania.
\end{abstract}

\section{Introduction}

In industry, often occurs accidents caused by fires / explosions (gas, dust or hybrid mixtures) that can cause damage to equipment, damage to people and the environment (in the event of an explosion at a chemical plant, which can cause pollution massive environmental damage), the closure of the factory, or even its complete destruction, leading to heavy losses, including, unfortunately, human lives. Although the risk of fire / explosion has been well known for decades, the destructive and repetitive nature of these phenomena has pushed scientists towards the progress of knowledge in order to anticipate, prevent and reduce the effects of explosions. Although progress has been made in recent years in terms of flammable / explosive behavior, further research is needed. Standards for good engineering practices have been developed worldwide. The American Fire Protection Association (NFPA) defines any organic dust with a surface-to-volume ratio larger than that of a sphere with a diameter of 420 microns as a potential hazard. Today, industrial and safety management specialists are aware of the dangers arising from familiar powders such as sugar, coffee, cocoa powder, wheat flour, but also waste / residues from technological processes. Analyzing the literature, the so-called black powder was identified, which is found as a residue that appears in the transmission pipelines at most natural gas distribution operators. It can take many forms, including wet tar or fine dry powder (Figure 1). Black dust occurs in both newer and older natural gas pipelines. This can disrupt the distribution of natural gas either by interrupting distribution to the customer or by reducing the quality of products delivered to customers [1-5].

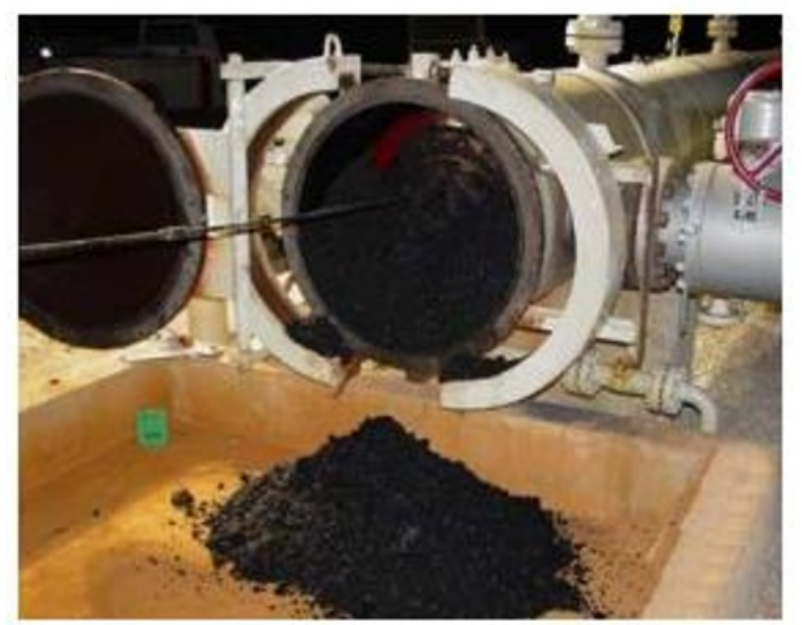

Fig. 1. Dry blackpowder [1]

This residue, black powder can damage operations that take place in the transport pipelines, such as reduced inspection accuracy, erosion of the control valve and reduced flow [2]. In addition, this powder also presents a health hazard due to the fact that it may contain pyrophoric sulphides, which require specific handling and storage procedures [3]. Black powder is a solid

* Corresponding author: maria.prodan@insemex.ro 
contaminant found in natural gas distribution systems around the world. Chemical or biological reactions with the steel in the transport pipelines can lead to its formation. Drilling mud, dust, construction dirt, sand, iron oxide, iron carbonate, iron sulfides, welding slag, salt crystals, valve grease, corrosion inhibitors, and other organic materials can contribute to the formation and the presence of this residue, also called black powder [1], [35]. In most cases, this residue is generated by the corrosion of the pipes, caused by the wet gas, respectively gas that contains enough water vapor to generate corrosion. Corrosion cannot occur if there is no water in the pipe, although gas with a relative humidity higher than $69 \%$ can cause minor corrosion if there are salts or acid gases in the pipe that absorb the water [2-6]. Natural gas corrosion agents include carbon dioxide, hydrogen sulfide, oxygen, organic acids such as acetic acid and bacteria. Correlations for corrosion rates from these compounds are available individually, with a few rules for determining which species takes control when both carbon dioxide and hydrogen sulfide are present. What is often omitted is oxygen. Oxygen behaves like a cathodic depolarizer, which breaks the polarization film that represents the step of controlling the corrosion rate, thus increasing the speed [1-7]. Other compounds identified in the black powder include iron oxides, sand, salts, clay, desiccants such as silica gel and other construction debris. Sometimes when there is a change of direction at a gas installation, the remaining debris can be swept into the pipe [8]. Black powder is made up of various forms of iron sulfur, iron oxide and iron carbonate mixed mechanically or chemically reacted with a number of contaminants such as salts, sand, liquid hydrocarbons and metal scrap. Different operators reported different compositions for the black powder removed from the transport pipes. In the specialized literature, iron sulfides and iron oxides have been predominantly reported in the composition of black powder [2-8]. Internal corrosion of natural gas transmission pipelines is the main cause of the formation of black powder residue [9]. Corrosion due to hydrogen sulfide, carbon dioxide and oxygen follow predetermined mechanisms [4], [10-12].

\subsection{Problems caused by black powder residue}

\subsubsection{Pyrophoric iron sulfides}

Iron sulfide is a pyrophoric material that will ignite when exposed to air. Figure 2 shows a separator filter on a gas pipe that has been opened for cleaning. The vessel was initially purged with carbon dioxide to minimize fire and once opened was continuously purged with water to prevent ignition. White smoke is observed, representing the oxidation of iron sulfide to sulfur dioxide and iron oxide just before catching fire [10].

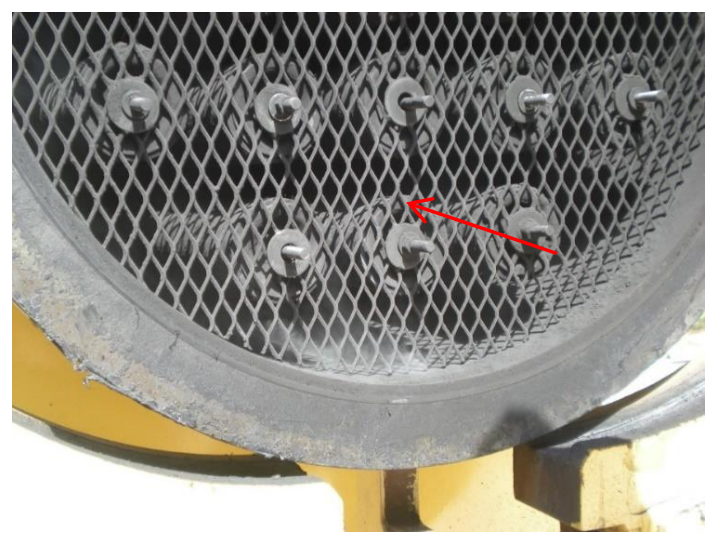

Fig. 2. Black powder filter right at the opening [10]

The figure below (Figure 3) shows some filter elements after removal from the separator, which caught fire immediately after removal. Materials contaminated with black powder and iron sulfur should be watered immediately after exposure to air.

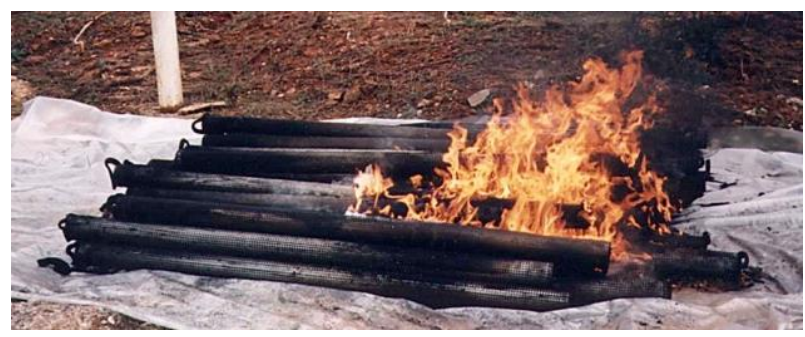

Fig. 3. Elements contaminated with black powder and iron sulfide after exposure to air $[1,10]$.

\subsubsection{Abrasiveness of black powder}

Black powder is very abrasive for compressor and gas generators. The figure below (Figure 4) shows a disc of a centrifugal compressor that resisted one day after the black powder entered the gas. In this case, an increase in the flow in the pipe caused the speed with which the black powder is transported to increase and flood the installation, and the filters could not be changed in time.

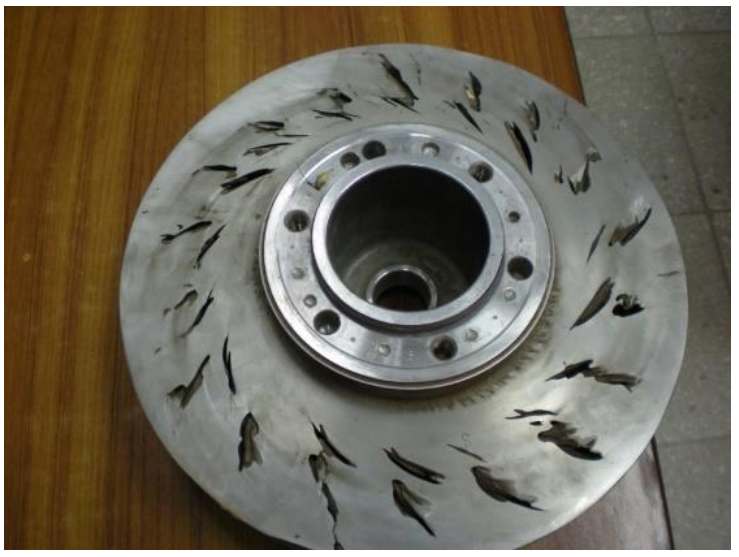

Fig. 4. The rotor of a centrifugal compressor eroded in one day due to black powder [10] 


\subsubsection{Deposits of black powder on the gas turbine blade}

The figure below (Figure 5) shows a blade of a gas turbine that was eroded at the time of contact with the black powder. The source of the black powder was located more than $120 \mathrm{~km}$ upstream, where cleaning operations were carried out with the godevil. Although there were filters, the issue was not solved [10].

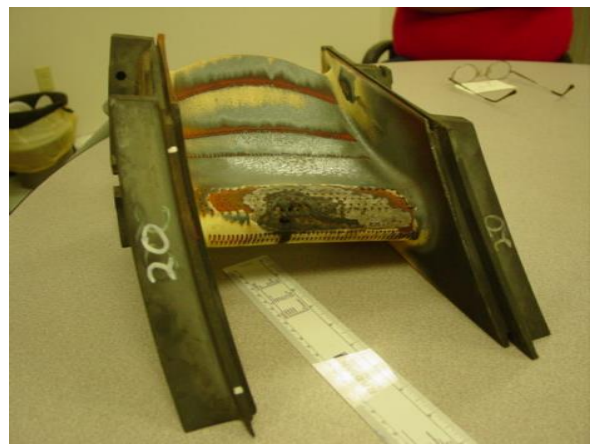

Fig. 5. Gas-cooled turbines, eroded by black powder [10]

\subsubsection{Low efficiency in pipes}

The black powder that blocks the pipes leads to a low efficiency of the transported gas. The figure below (Figure 6) shows a receiving terminal of a godevil blown to remove black dust.

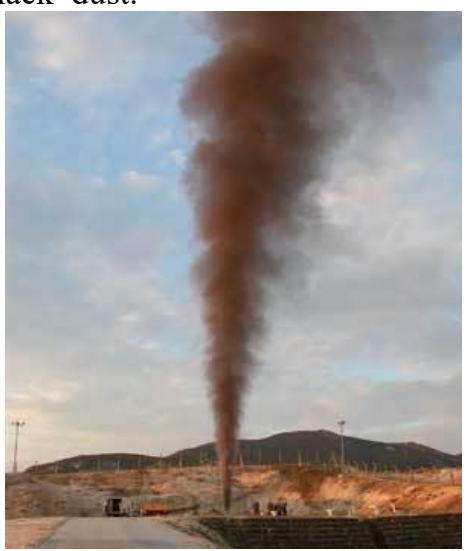

Fig. 6. Pig Receiver in terminal in Greece being blown down to remove black powder [10]

\section{Material and methods}

In order to determine the chemical composition, the presence of pyrophoric sulfides was monitored. 3 samples were analyzed as follows (Figure 7-9):

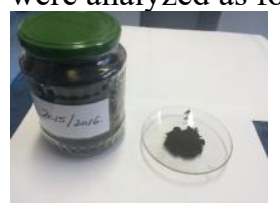

Fig. 7. Sample no 1 , residue from 2015/2016

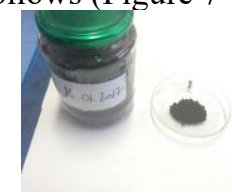

Fig. 8. Sample no. 2: residue from 16.01.2017

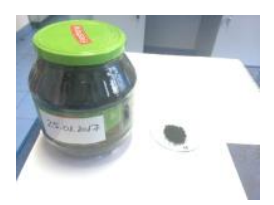

Fig. 9. Sample no. 3: residue from 25.01.2017
For the sample colected from the natural gas pipeline were perfomed the following analysis:

- Pyrophoric sulfides identification by chemical reaction with hydrocloric acid and instrumental determination;

- Calitative identification using Fourier Transform Infrared Spectroscopy. In order to establish the chemical composition of the residue samples collected from the natural gas transmission pipelines, they were analyzed by infrared spectrometry, with a FTIR equipment type Nicolet IS 50, manufacturer ThermoScientific, with integrated ATR module, with diamond crystal, in the field $4000-400 \mathrm{~cm}-1$, Figure 10. Infrared absorption spectra were recorded at a resolution of $4 \mathrm{~cm}-1$ by using the ATR analysis technique, attenuation of total reflection, performed directly on the residue samples - nondestructive analysis; 32 scans were performed for each spectrum. The experimental data obtained were evaluated using OMNIC software (Thermo Nicolet Corporation).

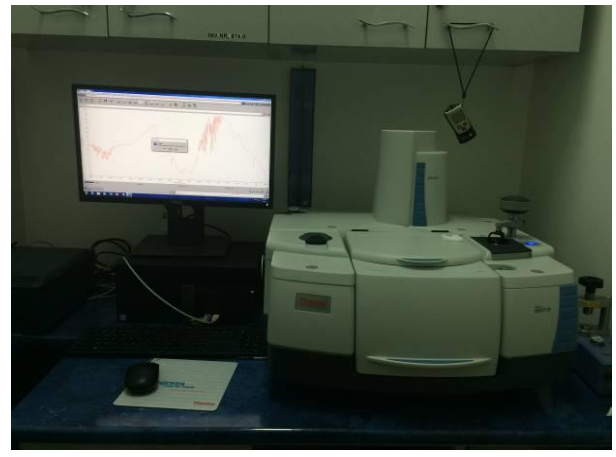

Fig. 10. FTIR equipment type Nicolet IS 50

- ICP OES metals identification using Perkin Elmer equipment (Figure 11) and Anton Paar digestor for the solid sample preparing. For the preparation of solid samples it is necessary to digest (bring in solution) by acid mineralization, with royal water (concentrated hydrochloric acid and concentrated nitric acid in a ratio of 3: 1), using the microwave mineralizer. The mineralized samples were filtered and brought into solution and analyzed by inductively coupled plasma optical emission spectrometry.

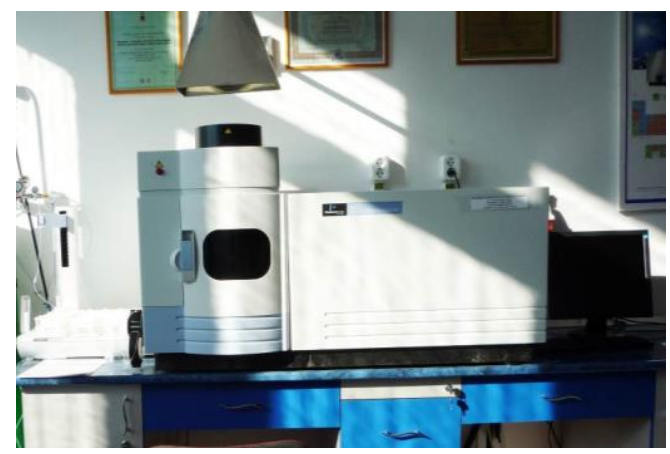

Fig. 11. Perkin Elmer ICP-OES

- Determination of the cloud minimum ignition temperature and layer ignition temperature using Anko Lab equipments (Figure 12 and 13) for this specific flammability dust analysis. 


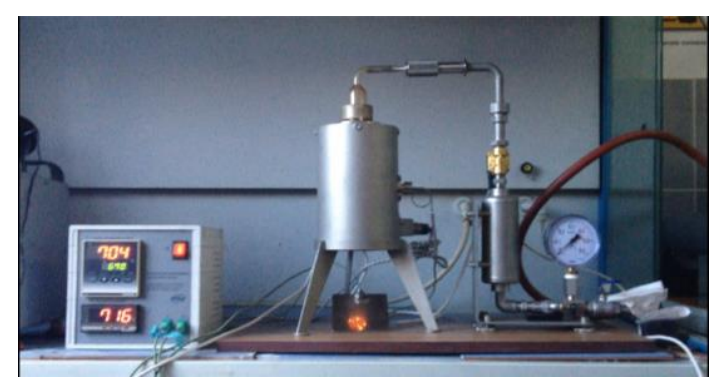

Fig. 12. Minimum ignition cloud temperature equipment

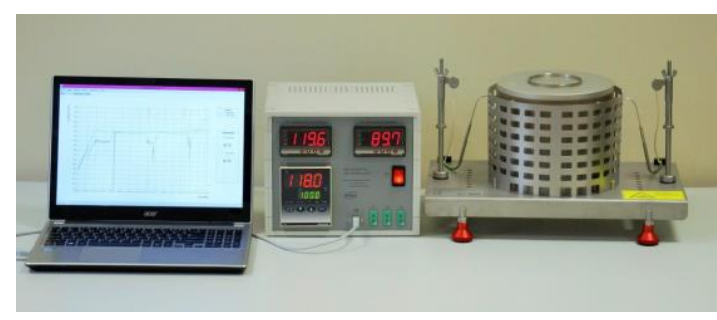

Fig. 13. Minimum ignition dust layer temperature equipment

- Self ignition behavior of dust accumulations determination (Figure 14) using a specific standard EN 15188:2007

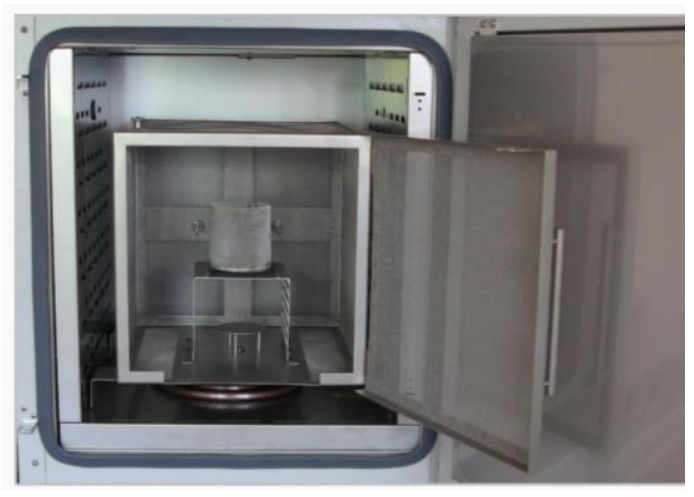

Fig. 14. Experimental assembly for hot steaming tests

\section{Results and discussions}

\subsection{Pyrophoric sulfides identification}

From the samples taken, described above, $2 \mathrm{~g}$ samples were prepared (Figure 7,8,9), which were subjected to the action of hydrochloric acid. Hydrochloric acid reacts with iron sulfide and hydrogen sulfide $\left(\mathrm{H}_{2} \mathrm{~S}\right)$ with a characteristic odor (unpleasant odor of boiled eggs) will be released. The smell of hydrogen sulfide can be detected at concentrations of a few ppm.

Following the reaction between iron sulfide and hydrochloric acid, $\mathrm{H}_{2} \mathrm{~S}$ (hydrogen sulfide) was formed, its concentration being recorded instrumentally, using the portable detector MSA ORION Plus.

$$
\mathrm{FeS}+2 \mathrm{HCl} \rightarrow \mathrm{FeCl}_{2}+\underset{\text { sulfide }}{\mathrm{H}_{2} \mathrm{~S} \uparrow \text { (formation of hydrogen }}
$$

After subjecting the samples to the action of hydrochloric acid, the release of gaseous reaction products (gas bubbles) and a greenish precipitate was observed (Figure 15). This color is specific to the formation of ferrous chloride. A concentration of $46 \mathrm{ppm}$ $\mathrm{H}_{2} \mathrm{~S}$ was measured (Figure 16).

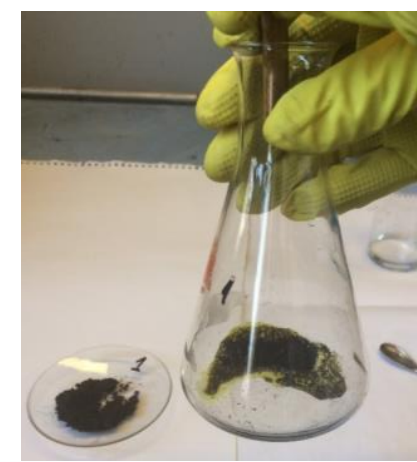

Fig. 15. Release of gaseous reaction products and greenish precipitate for sample no. 1

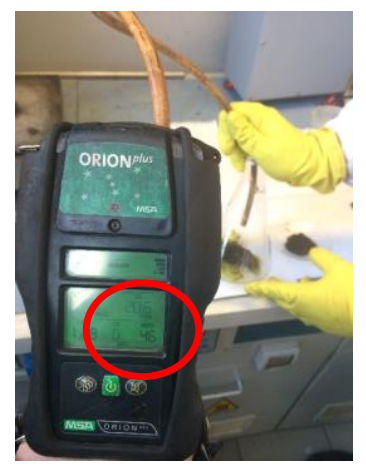

Fig. 16. Instrumentally measured $\mathrm{H}_{2} \mathrm{~S}$ concentration
Note: The presence of hydrogen sulfide was also detected by its characteristic odor for all samples analyzed.

From the results of laboratory tests performed on the samples, the following can be concluded:

- in the samples taken and tested there was identified iron sulfide, by means of its reaction products, products resulting from the reaction with hydrochloric acid, respectively hydrogen sulfide and ferrous chloride;

- following the reaction between iron sulfide and hydrochloric acid, $\mathrm{H}_{2} \mathrm{~S}$ (hydrogen sulfide) was formed, their concentrations being recorded instrumentally, using the portable detector MSA ORION Plus. In addition, ferrous chloride was identified, resulting from the reaction as a greenish reaction product;

- the existence of iron sulfide confirms the existence of pyrophoric sulfides, which can be a source of efficient ignition of flammable hydrocarbon-air mixtures.

\subsection{FTIR Analysis}

In the analysis of the samples, by comparing the IR spectrum with the database, a probability (match) of the spectrum of the residue with that of iron carbonate, also called siderite, was obtained (Figure 17). Matching with cadmium carbonate and asphalt was also found in the database.

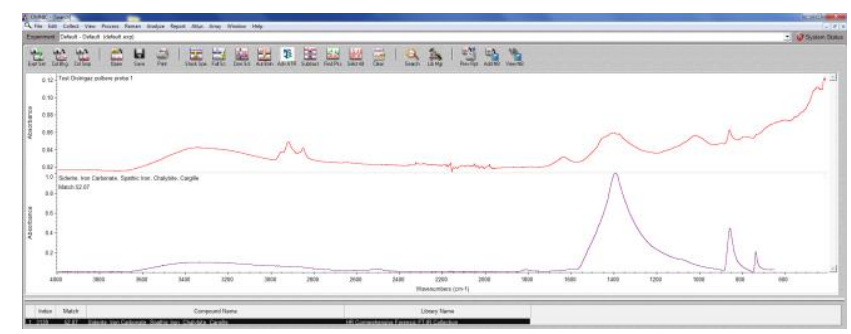




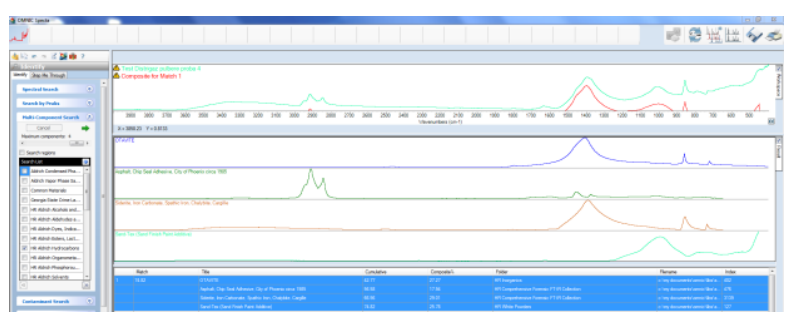

Fig. 17. IR Spectrum for sample no. 1

\subsection{ICP-OES ANALYSIS}

Table 1. Results from ICP-OES determination

\begin{tabular}{|c|c|}
\hline Metals & Sample no. 3 \\
\hline $\mathrm{Ca}$ & $7727 \mathrm{mg} / \mathrm{kg}$ \\
\hline $\mathrm{Fe}$ & $383400 \mathrm{mg} / \mathrm{kg}$ \\
\hline $\mathrm{Mg}$ & $2251 \mathrm{mg} / \mathrm{kg}$ \\
\hline $\mathrm{Al}$ & $3531 \mathrm{mg} / \mathrm{kg}$ \\
\hline $\mathrm{K}$ & $11270 \mathrm{mg} / \mathrm{kg}$ \\
\hline $\mathrm{Mn}$ & $4425 \mathrm{mg} / \mathrm{kg}$ \\
\hline
\end{tabular}

In the table 1 the identified metals are presented, as well as their proportion in the material, suggest, in addition to the other analyzes performed, that the analyzed residue is the so-called black powder generated by the corrosion process of natural gas pipelines.

\subsection{The minimum ignition cloud temperature determination}

The temperature increase took place in steps of $50 \mathrm{~K}$ until the appearance of the ignition, which took place at $700^{\circ} \mathrm{C}$, Figure 18. Next the dust mass and the dispersion pressure were increased progressively, in order to obtain the strongest ignition, which was obtained at a mass of $0,4 \mathrm{~g}$ and a dispersion pressure of 0,4 bar. By reducing the temperature in steps of $20{ }^{\circ} \mathrm{C}$, at the same dust mass of $0.4 \mathrm{~g}$, respectively dispersion pressure of $0.4 \mathrm{bar}$, the ignition temperature was obtained, confirmed by 10 tests of $580{ }^{\circ} \mathrm{C}$

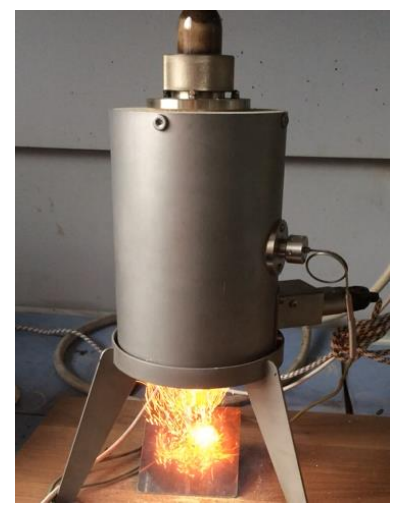

Fig. 18. Ignition of dust cloud

According to the method standard, respectively SR EN 50281-2-1: 2003 / AC: 2013 - "Electrical equipment intended for use in the presence of combustible dust. Part 2-1: Test methods - Methods for determining the minimum ignition temperature "The minimum ignition temperature shall be recorded as the lowest furnace temperature at which the ignition was obtained with the specified procedures, minus $20 \mathrm{~K}$ for the temperatures in oven above $300{ }^{\circ} \mathrm{C}$, so the minimum ignition temperature of the dust cloud for the residue sample was $560^{\circ} \mathrm{C}$.

The results obtained highlight the fact that the tested powder is a reactive powder from the point of view of explosiveness, which requires the taking of explosive protection measures that are required in its handling.

\subsection{Determination of minimum ignition layer temperature}

The aim was to determine the ignition temperature of the combustible dust layer, according to SR EN 50281-2-1: 2003 - "Electrical apparatus intended for use in the presence of combustible dust. Part 2-1: Test methods Methods for determining the minimum temperature of ignition of dust ", Figure 19.

To determine the ignition temperature of the layer for the residue sample, it was prepared according to the test method, respectively drying to remove soaking and granulation moisture at $200 \mu \mathrm{m}$.

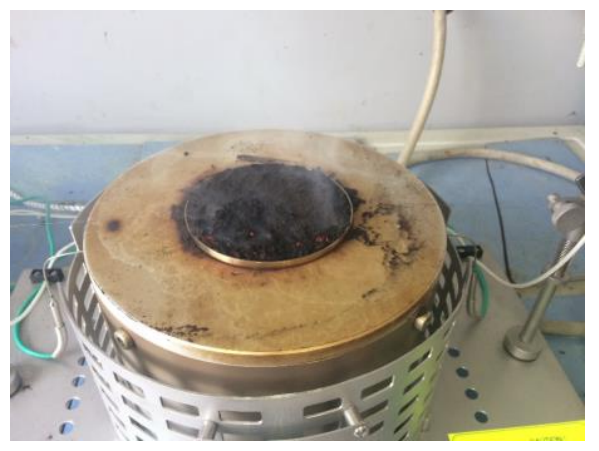

Fig. 19. Glow at minimum ignition temperature

It started with the temperature set at $400^{\circ} \mathrm{C}$. Ignition was obtained, evaluated by the appearance of the glow, continuing with the decrease of the temperature in steps of $50 \mathrm{~K}$ until the determination of the minimum ignition temperature, respectively $285^{\circ} \mathrm{C}$, for each test using a fresh layer of dust.

The result obtained, in addition to those obtained in determining the ignition temperature of the dust cloud, show that the tested powder is a reactive powder in terms of explosiveness and requires the taking of explosion protection measures required in its handling.

\subsection{Self-ignition behavior of dust accumulations}

The self-ignition of combustible dusts depends on their chemical composition as well as on the properties of the substances in the composition. It also depends on the particle size and geometry of the mass of the material and last but not least on the ambient temperature.

The underlying cause of self-heating (or possibly selfignition) is that molecules on the surface of combustible dust particles are subjected to exothermic reactions with oxygen in the air transported in the free volume between particles, even at normal temperatures. Any amount of 
heat released will then cause an increase in temperature in the reactive dust-air system, thus accelerating the reaction of other dust molecules with oxygen. In the Figures 20 and 21 there can be seen the graphical representation of ignition temperatures after Arhenius and induction time dependence function of volume/surface ratio.

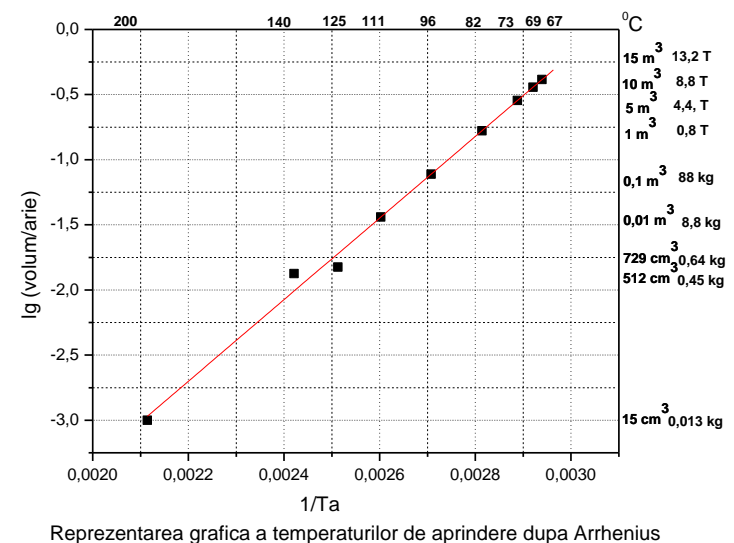

Fig. 20. Graphical representation of ignition temperatures after Arhenius

Interpretation:

Ex: an $88 \mathrm{~kg}$ quantity of bulk residue has a self-ignition temperature of $96^{\circ} \mathrm{C}$.

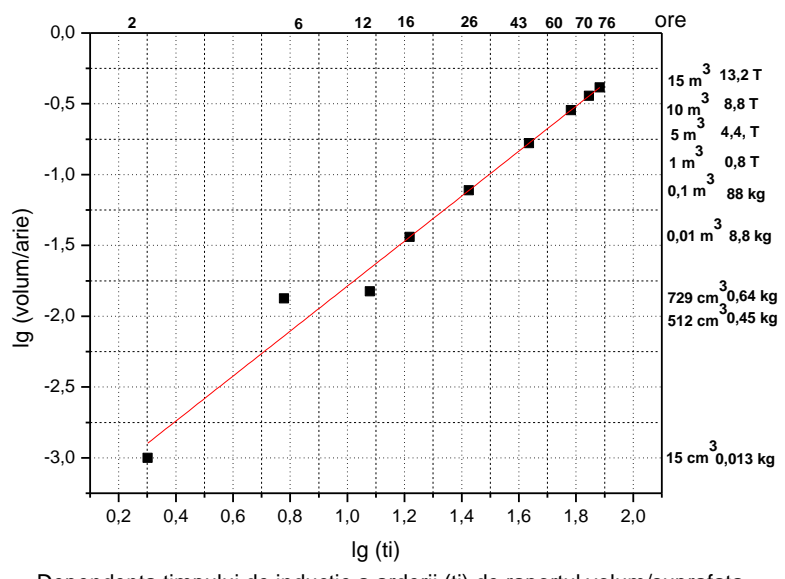

Dependenta timpului de inductie a arderii (ti) de raportul volum/suprafata

Fig. 21. Induction time dependence function of volume/surface ratio

Interpretation:

Ex: an $88 \mathrm{~kg}$ quantity of bulk residue gets to self-ignition if it is subjected to a temperature of $96^{\circ} \mathrm{C}$ after 28 days.

\subsection{Technical organizational measures for the handling and storage of the residue collected from natural gas transport pipes}

The dusts tested are combustible dusts that can generate a fire / respectively can form an explosive atmosphere and consequently adequate protection measures must be taken both to prevent the formation of the explosive atmosphere and to prevent ignition sources or, as the case may be, to limit the effects of explosions.

Based on the tests performed in this paper, the following measures can be formulated:
- in terms of the risk of self-ignition, due to the presence of pyrophoric sulphides, at the time of opening the filter for cleaning, if white smoke is observed, characteristic of their oxidation, either inerted with nitrogen or carbon dioxide or sprayed with water;

- also, to avoid self-ignition when opening the filter, you can also use sand or calcium carbonate powder, which will be mixed with the residue;

- in view of the minimum ignition temperatures determined, $285^{\circ} \mathrm{C}$ in the layer and $560^{\circ} \mathrm{C}$ in the cloud, the use of equipment which may produce these temperatures in operation, as well as the turbulence of the dust, shall be avoided;

- explosion protected equipment will be used;

- given the self-ignition behavior of dust accumulations, temporary storage (from extraction to delivery to the waste processor) must be carried out in non-combustible, airtight containers, and in the situation where white smoke is observed, characteristic of oxidation of iron, spray the residue with water or mix with sand or calcium carbonate, if there is no possibility of inerting with nitrogen or carbon dioxide.

- when storing the residue in non-combustible containers, it is recommended to place a layer of sand or calcium carbonate on top of the residue;

\section{Conclusions}

From the results of laboratory tests performed on the samples, the following can be concluded:

- In the samples taken and subjected to the tests, iron sulfide was identified, by means of its reaction products, products resulting from the reaction with hydrochloric acid, respectively hydrogen sulfide and ferrous chloride;

- Following the reaction between iron sulfide and hydrochloric acid, H2S (hydrogen sulfide) was formed, their concentrations being recorded instrumentally, using the portable detector MSA ORION Plus. In addition, ferrous chloride was identified, resulting from the reaction as a greenish reaction product;

- The existence of iron sulfide confirms the existence of pyrophoric sulfides, which can be an efficient source of ignition, both for the residual powder and for any combustible material in the vicinity;

- The results obtained from the FTIR analysis showed a match of the IR spectra with the spectrum of Siderite (Iron Carbonate), a substance identified in the composition of the black powder residue described in the introduction;

- Also, the identified metals, as well as their proportion in the material suggest, in addition to the other analyzes performed, that the analyzed residue is the so-called black powder generated by the corrosion process of natural gas pipelines.

- The results obtained when determining the ignition temperature of the cloud, respectively of the combustible dust layer, highlight that the tested powder is a reactive powder from the point of view of explosiveness and requires the taking of explosion protection measures that are required in its handling. 
- The bulk self-ignition temperature of the powder has been determined, from which a maximum amount can be estimated and a time in which the residue can be stored so that self-ignition does not occur.

\section{References}

1. F. Mueller, Winning the war against black powder, http://www.muellerenvironmental.com/res/uploads/ media/BlackPowder-A_reformatted_1.pdf

2. M. Sahdev, Pryophoric iron fires, Cheresources Online Chemical Engineering Information, (2010)

3. A.C. Hoffmann, L.E. Stein, Gas Cyclones and Swirl Tubes, Springer-Verlag Berlin Heidelberg, pp. 183-211 (2008)

4. W. Peng, A. Hoffman, H. Dries, Separation Characteristics of Swirl-Tube Dust Separators., AIChE Journal, 50, pp. 87-96, (2004)

5. T.M. Nieuwstadt, M. Dirkzwager, A Fluid Mechanics Model for an Axial Cyclone Separator., Ind. Eng. Chem. Res., 34, pp. 3399-3404, (1995)

6. R. S. Postma, A. C. Hoffmann, H. W. Dries, C. P. Williams, The Use of Swirl Tubes for Dedusting., World Congress on Particle Technology 3, pp. 1-8, (1998)

7. T. Akiyama, T. Marui, Dust Collection Efficiency of a Straight-Through Cyclone - Effects of Duct Length, Guide Vanes and Nozzle Angle for Secondary Rotational Air Flow, Powder Technology, 58, pp. 181-185, (1989)

8. National Project PN 16-43-03-02, Research on the influence of pyrosulphides in the production of explosion or fire events", Project manager, dr. Maria Prodan, (2016-2017);

9. A. N. Tsochatzidis, E. M. Konstantinos, Methods help remove black powder from gas pipelines, Oil and Gas Journal, 105, pp. 52-58, (2007)

10. J. S. Smart, Black powder in gas pipelines, Texas Gas Associationn Conference, (2014),

11. T.H. Wines, Black Powder Removal from Transmission Pipelines: Diagnostics and Solutions,, Pipeline Rehabilitation \& Maintenance Conference, Gulf International Convention Center, Bahrain, , (2009)

12. M. Alshehhi, S. Stephen, L. Khezzar, Characterization and preliminary root cause identification of black powder content in a gas transmission networ, Journal of Natural Gas Science and Engineering, 27, pp. 769-775, (2015) 